\title{
Development Trend Analysis of China National Standardization Guidance Technical Documents-Based on the Study of China and ISO Standards System
}

\author{
Jia LI 1,a, ${ }^{,}$, Zheng-Hu PANG ${ }^{2, b}$ \\ ${ }^{1,2}$ China National Institute of Standardization, No. 4 Zhichun Road, Beijing, China \\ alijia@cnis.gov.cn, bpangzhh@cnis.gov.cn \\ ${ }^{*}$ Corresponding author
}

Keywords: China standards system, ISO standards system, National guidance technical documents.

\begin{abstract}
By comparing analysis between China standards system and ISO standards system and revealing the correspondence relationships between different types of standardization documents, and based on the aim of national guidance technical documents, this paper explored the development tend of national guidance technical documents in terms of positioning, standardized objects, technical contents and the development and revision procedures, intending to help the standardization workers to compile accurate and normative standardization documents.
\end{abstract}

\section{Introduction}

In China, standardization publications on national level consist of national standards and national standardization guidance technical documents. According to Management Regulation on national standardization guidance technical documents (hereinafter referred to as the Management Regulation) published in 1998, national standardization guidance technical documents (hereinafter referred to as the guidance technical documents) are standardization documents that provide guidance or information on standardization work which is still under technical development (e.g. rapidly evolving technology fields)[1]. The guidance technical documents, as a kind of standardization document, are created to respond to rapidly evolving technologies and market needs and to transform technical reports of international standardization organization (ISO) into Chinese standardization documents.

As the development and revision procedures of guidance technical documents are almost the same as the procedures of national standards, people are often confused with relations between them and their respective orientations. Some mistakenly assumed that if it was difficult for a national standard to be approved, a technical document would be an alternative. As a result, some of the technologies that have already matured are still in the form of guidance technical documents. Moreover, ISO has divided its technical reports into technical specifications and technical reports, and a great number of new form standardization documents of international and foreign standardization organizations are emerging, some international and foreign technologies that have not yet matured were transformed into national standards in China because certain percentage of applicants weren't familiar with the characteristics and the development procedures of new form standardization documents.

As rapidly development of new technologies, strongly demand for transforming scientific and technological achievements and the emergence of new form standardization documents, the Management Regulation have not satisfied the need of guidance technical documents in China. According to the actual situation in our country, combined with international and foreign advanced experience, the future guidance technical documents shall make reasonable adjustments in terms of its positioning, standardized objects, main technical contents and the development and revision procedures and so on, to adapt to the technical innovation and transformation of scientific and technological achievements and to promote international communication. 


\section{Relationships between Chinese Standards System and ISO Standards System \\ ISO Standards System Framework}

In addition to international standards (IS) which is the most famous publication, ISO has other publications such as technical specification (TS), technical report (TR), publicly available specification (PAS) and international workshop agreement (IWA).

An international standard refers to a standard developed by ISO, which provides world-level specifications for products, services and systems, aimed at ensuring quality, safety and efficiency and promoting international trade. By Aug. 24, 2017, ISO has published 21,788 international standards and other publications, dealing with a nearly full range of fields such as technologies, food safety, agriculture and health care, about 9.5 percent of which are the publications except international standards [2].

TS, TR, PAS and IWA are new ISO publications, which are published to respond to rapidly changing economics and an urgent market need. Therefore they are flexible in work procedures and documents form [2]. TS mainly addresses highly advanced technology field and are included in the serial number of international standard as they are little different from them in content, structure and format. TR contains data files different from that of international standards and technical specifications, and they are fully informative and clearly clarifies the relationship of normative content involved in national standards relating to thematic topics. PAS addresses highly advanced or rapidly evolving technologies. They are proposed by companies or associations and represent their consensus. After being harmonized with particular international standards, they will be published by ISO. IWA mainly focuses on fields which are not covered by existing technical organizations and experts, as well as rapid development fields in which traditional standards and development procedures cannot meet the market requirements for standardization.

An international standard is developed through such stages as preliminary, proposal, preparatory, committee, enquiry, approval and publication [3].A new project shall not pass the committee stage without a two-thirds majority vote of $\mathrm{P}$ members of its technical committee or subcommittee. It shall not pass the enquiry or approval stage without a two-thirds majority of $\mathrm{P}$ members of its technical committee or subcommittee voting for approval, at the same time not more than one-quarter of the total number voting are negative. Its deliveries shall not be published when it is not through the approval stage. TS, PAS or TR shall not be published when it is not through the committee stage. PAS or TR may be published only by a simple majority vote of P members of its technical committee or subcommittee, while TS shall not be published without a two-third majority vote of P member of its technical committee or subcommittee. Procedures for the development of IWA are independent of ISO's typical ones. IWA is produced through an open workshop agreement rather than through the full ISO technical committee process. It allows market players to negotiate on specific technical content designated by the workshop. Only consensus at the workshop or among drafting organizations is required rather than ISO consensus procedures. Table 1 shows ISO standardized documents project stages and passed conditions. 
Table 1 Project stages and associated documents

\begin{tabular}{|c|c|c|c|c|}
\hline \multirow{2}{*}{ Project stage } & \multicolumn{4}{|c|}{ Associated documents } \\
\hline & IS & TS & PAS & TR \\
\hline $\begin{array}{l}\text { Preliminary } \\
\text { stage }\end{array}$ & $\begin{array}{l}\text { Preliminary work } \\
\text { item(PWI) }\end{array}$ & PWI & PWI & PWI \\
\hline $\begin{array}{l}\text { Proposal } \\
\text { stage }\end{array}$ & $\begin{array}{l}\text { New work item } \\
\text { proposal (NP) }\end{array}$ & NP & NP & - \\
\hline $\begin{array}{l}\text { Preparatory } \\
\text { stage }\end{array}$ & Working draft(WD) & WD & WD & - \\
\hline $\begin{array}{l}\text { Committee } \\
\text { stage }\end{array}$ & $\begin{array}{l}\text { Committee draft(CD) } \\
\text { (two-thirds majority vote } \\
\text { of the P-members } \\
\text { voting) }\end{array}$ & $\begin{array}{l}\text { Draft Technical } \\
\text { Specification(DTS) } \\
\text { (two-thirds } \\
\text { majority vote of the } \\
\text { P-members voting) }\end{array}$ & $\begin{array}{l}\text { Draft Publicly } \\
\text { Available } \\
\text { Specification(DPAS } \\
\text { ) } \\
\text { (simple majority } \\
\text { approval of the } \\
\text { P-members voting) }\end{array}$ & $\begin{array}{l}\text { Draft Technical } \\
\text { Report(DTR) } \\
\text { (simple majority } \\
\text { approval of the } \\
\text { P-members } \\
\text { voting) }\end{array}$ \\
\hline $\begin{array}{l}\text { Enquiry } \\
\text { stage }\end{array}$ & $\begin{array}{l}\text { Enquiry draft (ISO/DIS) } \\
\text { (two-thirds majority vote } \\
\text { of the P-members } \\
\text { voting, and not more } \\
\text { than one-quarter of the } \\
\text { total number of votes } \\
\text { cast are negative) }\end{array}$ & |-- & |-- & |-- \\
\hline $\begin{array}{l}\text { Approval } \\
\text { stage }\end{array}$ & $\begin{array}{l}\text { final draft International } \\
\text { Standard (FDIS) } \\
\text { (two-thirds majority vote } \\
\text { of the P-members } \\
\text { voting, andnot more than } \\
\text { one-quarter of the total } \\
\text { number of votes cast are } \\
\text { negative) }\end{array}$ & |-- & |-- & |-- \\
\hline $\begin{array}{l}\text { Publication } \\
\text { stage }\end{array}$ & $\begin{array}{l}\text { International } \\
\text { Standard(IS) }\end{array}$ & $\begin{array}{l}\text { Technical } \\
\text { Specification(TS) }\end{array}$ & $\begin{array}{l}\text { Publicly Available } \\
\text { Specification(PAS) }\end{array}$ & $\begin{array}{l}\text { Technical } \\
\text { Report(TR) }\end{array}$ \\
\hline
\end{tabular}

\section{Comparing Analysis between Chinese Standards System and ISO Standards System}

Publications made by standardization authorities under the State Council in China consist of national standards and national guidance technical documents.

Management Regulation on National Standards provide the scope of national standards and their procedures for proposal, drafting, audit, approval, publication and review[4]. By Aug. 24, 2017, there have been 34,285 national standards [5], covering almost all sectors. As both global market and technical market are changing at a significantly rate, the Regulation have not satisfied the standards development demand in China. It is under revision at present.

Management Regulation on national standardization guidance technical documents provide the definition, scope, code rules and the development and revision procedures of national guidance technical documents [1]. By Aug. 24, 2017, there have been 377 guidance technical documents [5]. It is said that the regulation is currently under revision, considering that international standardization documents (except IWA) should be used as guidance technical documents. Figure 1 shows relationships between the future Chinese standards system and ISO standards system [6]. 


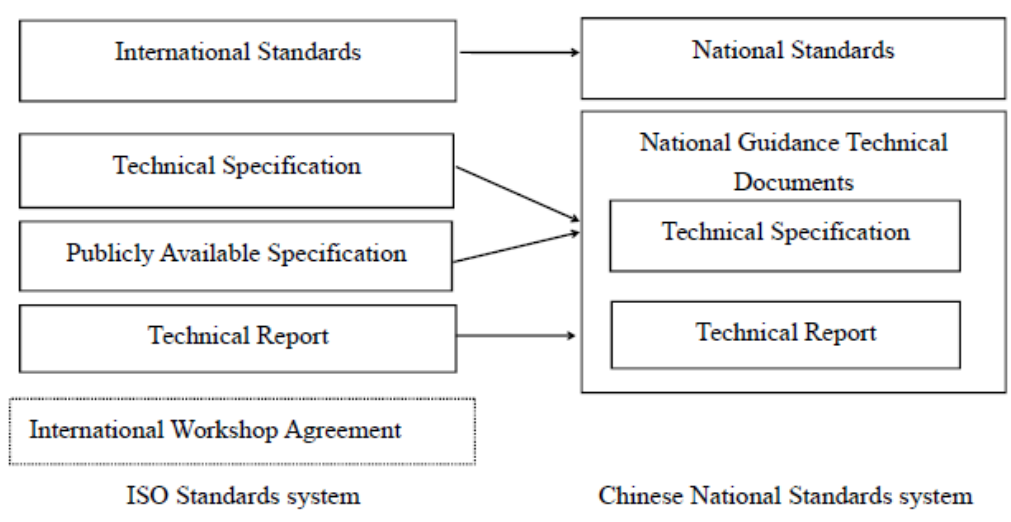

Figure 1 Relationships between Chinese standards system and ISO standards system

Figure 1 shows that China national standards correspond to IS in ISO standards system. By Aug. 24, 2017, China national standards have adopted 11978 standards published by international and foreign organizations, accounting for $34.9 \%$ of the total, with the adoption of ISO standards of $21.8 \%$ [5]. In future, national guidance technical documents could be classified into: 1) technical specifications, which correspond to ISO TS and PAS, and 2) technical reports, which correspond to ISO TR. By Aug. 24, 2017, national guidance technical documents have adopted 214 documents published by international and foreign organizations, accounting for $56.8 \%$ of the total, with the adoption of ISO documents of 22.3\% [5]. There aren't standardization publications at national level in China that correspond to ISO IWA. Considering that procedures for the development of IWAs are independent of ISO typical ones and they are proposed by companies or associations, it is recommended that they may be transformed into Chinese association standards or enterprise standards.

\section{Development Trend of China National Guidance Technical Documents}

\section{Positioning and Purpose}

As shown in Figure 2, guidance technical documents aren't classified as national standards but standardization documents in China. They are set to provide guidance or information on standardization work which is still under technical development (e.g. rapidly evolving technology fields) to researchers, designers, manufacturers, users and executives. To respond to rapidly evolving technologies, demand for the transformation of scientific and technological achievements and new form international and foreign standardization documents, future guidance technical documents shall be aimed at exploring for the development and application of formal standards, stimulating technical innovation and the transformation of technical achievements, promoting technical progress and industrial upgrading and facilitating international exchange, more than providing the guidance and information.

\section{Standardized Objects and Scope}

Program technical standard of science and technology development under the Twelfth Five-Year plan proposes that efforts shall be made to guide and support the development of technical standards for the emerging industries and promote the transformation of great technical achievements into national standards [7]. As technologies are proliferating in new industries, traditional procedures for the development and revision of standards haven't reflected market needs rapidly. Moreover, a trial and/or a preliminary plan for marketing are essential for many technical achievements to be industrialized and marketized at an initial phase, while traditional standard development models go against the transformation of new technical achievements because of preference for mature technologies and a long development cycle. Therefore a flexible and responsive guidance technical documents are necessary for transforming technical achievements timely and promoting advanced technologies. Emerging industries are characterized by: 1) new 
technologies, processes, materials or products, 2) immature or rapidly evolving technologies, and 3) potential value for standardization despite uncertain range of application and market prospect.

Moreover, in view that new international and foreign standardization documents, e.g. ISO TS, are produced to respond to an urgent market need and in transition to formal standards, or, e.g. ISO TR, just provide information, so China national guidance technical documents shall be adjusted to keep up with the development of international and foreign new standardization documents. Finally, an international standard, which doesn't fit Chinese conditions or application situation, shall not be transformed into a China national standard in a short term. It may be transformed into a guidance technical documents and when necessary, into a national standard.

\section{Selection of Main Technical Contents}

To be adapt to the positioning and purpose of guidance technical documents, the technical aim of future guidance technical documents may be adjusted as the provision of trail characteristics, guidance or information to the standardized objects of the documents, which contain technologies still under development.

The technical specifications of guidance technical documents in china, as trail standards, aren't different from national standards only in technical content. They shall likewise be subject to related requirements, as specified by basic national standards, for the selection of elements and the compile of technical contents. What is different is that they are intended for emerging or rapidly evolving technologies, with low maturity and low consensus. As the science and technology development, they would be withdrawn or transformed into national standards because technologies they include are likely to be replaced or eliminated.

The technical reports of guidance technical documents in china just provide informative or academic data. They shall be fully informative and shall not contain any statement through which they would be mistaken as a normative document. They may refer to related normative documents and so they are instrumental in their use. Technical reports shall not be transformed into national standards.

\section{Development and Revision Procedures}

China national standards shall be developed and revised in accordance with Management Regulation on National Standards, through such stages as preliminary, proposal, draft, enquiry, audit, approval, publication, review and withdraw. To respond to market demand timely and keep up with rapidly changing technologies, future guidance technical documents will be produced by streamlining the procedures and facilitating consensus, in line with the positioning of the guidance technical documents and in reference to procedures for the development and revision of related ISO standardization documents.

In contrast to a national standard, it is recommended that a draft of a guidance technical document is directly submitted to its technical committee for audit, not via enquiry stage. Criteria for consensus may be lowered, e.g. An national standard need three-fourths majority vote of the committee members voting for approval at preliminary or audit stage, and a guidance technical document need simple majority vote of the committee members voting for approval at audit stage. Finally, the content and form of audit at every stage may be streamlined.

The guidance technical documents shall be reviewed by type at review stage. It is unnecessary for a technical report to fix a review period, which is informative, corresponding to ISO TR and shall not be transformed into a national standard. As far as a technical specification is concerned, procedures for the review of ISO TS may be used, and the review period shall be shortened to three years and only after that, second review may be done. Moreover, the period of validity of a technical specification shall not be more than 6 years and after that, shall be withdrawn or transformed into a national standard whichever is appropriate.

\section{Conclusion}

China standards system is quite different from international and foreign ones, so although 
international and foreign standardization organizations are experienced in standards development, we still need to combine the standardization system in our country to propose the improvement plan after learning lessons from them. China national guidance technical documents are the only national level standardization documents in addition to national standards. They are applicable for the standardization of scientific and technological achievements in emerging fields with rapid technological development or rapid change. They provide a channel for transforming international and foreign standardization documents and standardize the standardization system of our country. It is necessary for standardization workers to understand their scope, selection of technical contents, development and revision procedures and compile the accurate and normative standardization documents.

\section{Acknowledgement}

This research was financially supported by Standardization Administration of the People's Republic of China Program "Research on National Standardization Guidance Technical Documents System "(No.: 572015B-4102).

\section{References}

[1] AQSIQ (1998) No.181, Management Regulation on national standardization guidance technical documents, Dec. 24, 1998

[2] ISO website, http://www.iso.org

[3] ISO/IEC Directives, Part 1, 2017, Consolidated ISO Supplement - Procedures specific to ISO

[4] AQSIQ Directive No.10, Management Regulation on National Standards, Aug. 24, 1990

[5]SAC website, http://www.sac.gov.cn

[6] Pang Zhenghu, Bai Dianyi and Li Wenwen, The development of New International Standardization Documents and policies of $\mathrm{China}[\mathrm{J}]$, World Standardization \& Quality Management, 2006,11:4-9

[7] Ministry of Science and Technology (2012) No. 1100, Program technical standard of science and technology development under the Twelfth Five-Year plan, Nov. 30, 2012 